\title{
Quantification of Sodium Pentobarbital Residues from Equine Mortality Compost Piles
}

\author{
Josh Payne, Ph.D., Rodney Farris, Ph.D., and Gene Parker, D.V.M. \\ Oklahoma State University, Stillwater, OK 74078 \\ joshua.payne@okstate.edu
}

Jean Bonhotal and Mary Schwarz

Cornell Waste Management Institute, Ithaca, NY 14853

\author{
Written for presentation at the \\ $4^{\text {th }}$ International Symposium: Managing Animal Mortalities, Products, \\ By-products and Associated Health Risk \\ Connecting Research, Regulations and Response \\ Dearborn, MI \\ May 21-24 2012
}

\begin{abstract}
Preliminary research has shown that sodium pentobarbital (SP), a euthanasia drug, can persist up to 180 days in equine mortality compost piles. This study attempts to expand upon past research by quantifying SP residues in equine mortality compost piles over a longer duration using innovative sampling schemes. Six, $3.7 \mathrm{~m}^{2}$ plots were used to construct separate compost bins with 3 bins serving as control. Each bin was constructed with $1.2 \mathrm{~m}$ high horse panels. The carbonaceous material consisted of wood chips that were added at a depth of $0.46 \mathrm{~m}$ creating the base. Twenty-four whiffle balls, pre-filled with wood chips were placed on the center of each pad. Nylon twine was tied to each ball for retrieval. Six horses requiring euthanasia for health reasons as determined by a licensed veterinarian were used for the study. The veterinarian supplied and humanely euthanized each horse. Each horse was sedated by injecting 8 $\mathrm{ml}$ of xylazine intravenously. Each of the three treatment horses were then euthanized by injecting $60 \mathrm{ml}$ of SP intravenously. Each of the three control horses were anesthetized by injecting $15 \mathrm{ml}$ of ketamine hydrochloride intravenously and then euthanized by gunshot to the temporal lobe. Immediately following euthanasia, each carcass was placed on the center of the woodchip pad and surrounded with $0.6 \mathrm{~m}$ of additional wood chips. Serum and liver samples were immediately obtained while whiffle ball, soil and compost samples were obtained over time. Each sample was analyzed for $\mathrm{SP}$ residues. Compost pile and ambient temperatures were also recorded. Preliminary data illustrates SP persistence up to 129 days in compost piles with no clear trend of reduction. Further sampling and analysis will be conducted.
\end{abstract}

Keywords. animal mortality, composting, carcass disposal, horse

The authors are solely responsible for the content of these proceedings. The technical information does not necessarily reflect the official position of the sponsoring agencies or institutions represented by planning committee members, and inclusion and distribution herein does not constitute an endorsement of views expressed by the same. Printed materials included herein are not refereed publications. For permission to reprint or reproduce please contact the lead author. Citations should appear as follows. EXAMPLE: Authors. 2012. Title of presentation. $4^{\text {th }}$ International Symposium on Managing Animal Mortality, Products, and By-products, and Associated Health Risk: Connecting Research, Regulations and Response. Dearborn, MI. May, 21-24, 2012. 


\section{Introduction}

Equine mortality is an issue encountered by every horse owner. Mortality may be associated with disease, injury, age or a catastrophic event. For horses suffering from an incurable illness or injury, euthanasia is often the most humane option. The American Veterinary Medical Association (AVMA) approved methods for horse euthanasia include barbiturate overdose and captive bolt or gunshot to the temporal lobe. Following mortality, the carcass must be properly disposed of. For many horse owners, carcass disposal options are limited and can be costly. Improper disposal of dead animal carcasses and the resulting leachate can negatively impact surface water and groundwater quality. If the animal died of an infectious disease, pathogens may be present inside the carcass, thereby increasing disease transmission risks.

Common methods for livestock mortality disposal include burial, incineration, rendering, landfills and composting. Burial requires that certain environmental guidelines be followed, requires heavy equipment, may temporarily disturb the land needed for grazing and brings the carcass closer to the water table. Incineration requires a closed air unit, can be costly and is mainly designed for smaller animals; dismemberment may be required for larger carcasses. Although rendering is a very effective method for carcass disposal, currently there are very few rendering services available. Landfilling requires transportation of the dead animal off-site and may be emotionally unpleasant for the horse owner.

Composting horse mortalities is an inexpensive, biosecure and environmentally sound approach to addressing the issue of carcass disposal. By definition, composting is a controlled biological decomposition process that converts organic matter into a stable, humus-like product.

Composting animal carcasses is characterized by the breakdown of a large centralized nitrogen source (carcass) that is surrounded by a carbon source (bulking agent). This system requires an initial breakdown of the soft tissues on the exterior of the carcass, followed by thorough mixing to promote an ideal blend of carbon and nitrogen for effective composting. The bulking agent also traps leachate and odors produced during the process, therefore acting as a filter between the carcass and the environment. The continuous high temperatures $\left(>55^{\circ} \mathrm{C}\right)$ achieved through proper composting will destroy most pathogens and viruses (Kalbasi et al., 2005). Microorganisms will eventually degrade the carcass leaving only a few remaining bones. This valuable by-product can then be land applied as a fertilizer source, recycling nutrients and organic matter to the soil, or reused for additional mortalities.

Recent interest has focused on the common euthanasia barbiturate, sodium pentobarbital (SP), and its persistence in the animal carcass following euthanasia. In 2003 the FDA added environmental warning labels to pentobarbital containing euthanasia products in regards to proper carcass disposal (FDA, 2003). Questions exist regarding the potential environmental risk if SP euthanized animal carcasses are improperly disposed of. It has been suggested that proper composting of animal carcasses euthanized with SP may reduce drug residues to negligible concentrations. However, preliminary research has shown that SP can persist up to 180 days in equine mortality compost piles (Cottle et.al, 2010). This study attempts to expand upon previous research by quantifying SP residues in equine mortality compost piles over a longer duration using innovative sampling schemes.

\section{Materials and Methods}

The study was conducted at the Oklahoma State University Eastern Research Station located in Haskell, OK. Six, $3.7 \mathrm{~m}^{2}\left(12 \mathrm{ft}^{2}\right)$ plots were used to construct separate compost bins. Three of 
the six bins were used as control plots. The bulking agent for construction of compost piles consisted of wood chips that were wetted to approximately $45 \%$ moisture content. Each compost bin was constructed with $1.2 \mathrm{~m}$ (4 ft.) high horse panels supported by 3 steel t-posts. Bulking agent was added at a depth of $0.46 \mathrm{~m}$ (18 in.) creating the pad (Figure 1). Twenty-four whiffle balls pre-filled with wood chips were placed on each pad (4 rows of 6 ) such that they were under the horse. Nylon hay twine was tied to each whiffle ball for retrieval during required sampling times.

Six horses requiring euthanasia for health reasons as determined by a licensed veterinarian were used for the study. The horses were at the end of their life or suffering from terminal disease. No animal was euthanized solely for research purposes. A licensed veterinarian supplied and humanely euthanized each horse prior to the research team taking possession of the carcasses. Each horse was first weighed and then sedated by injecting $8 \mathrm{ml}$ of xylazine intravenously. Each of the three treatment horses were then euthanized by injecting $60 \mathrm{ml}$ of SP (Beuthanasia-D, Schering-Plough Animal Health) intravenously. Each of the three control horses were anesthetized by injecting $15 \mathrm{ml}$ of ketamine hydrochloride intravenously and then euthanized by precise gunshot to the temporal lobe.

Immediately following euthanasia, each carcass was placed on the center of the pad while

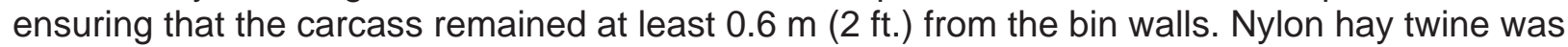
used to secure the head and legs near the carcass core. Three serum samples and 1 liver sample were taken from each carcass for SP analysis, representing time 0. Each serum sample was drawn from the contra lateral jugular and was placed in a red top vacutainer tube. A section of the liver weighing approximately $100 \mathrm{~g}$ was removed and placed in sealed plastic bags. All samples were placed on ice and transported to the laboratory for analysis. Two HOBO Temperature Data Loggers (Onset, Inc. Bourne, MA) were placed in each bin. One logger was placed over the front quarter while one logger was placed over the hind quarter of each carcass. The loggers were set to record temperature hourly. The carcass was then surrounded with 0.6 $\mathrm{m}$ (2 ft.) of additional wood chips (Figure 2). Core temperature of each pile was also recorded in triplicate using long-stem thermometers. Ambient temperature was recorded by a weather station located next to the Experiment Station.

Figure 1. Compost bin with pad.

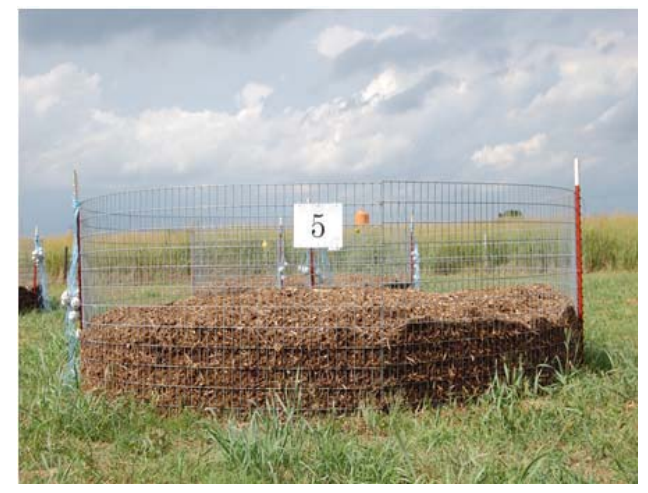


Figure 2. Compost bin after carcass placement.

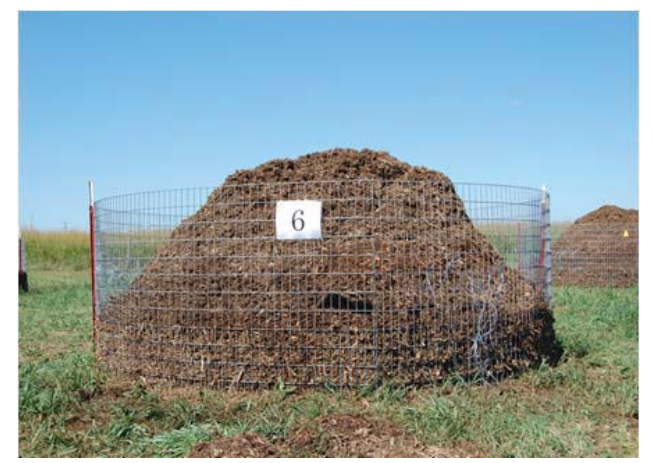

Three, composite core soil samples were taken from within each treatment bin and analyzed for SP on day -1 . Additional soil samples will be taken within each bin at the conclusion of the study. Composite samples consisted of $15 \mathrm{~cm}$ (6 in.) core soil samples from 15 collection points within each bin. Each composite sample was thoroughly mixed and then pooled in a sealed plastic bag. Three whiffle balls were collected from each bin on days $7,10,14,28,56,84$, and 129 of composting and analyzed for SP concentrations. On day 129, the treatment piles were opened and examined for bone and tissue remains. Periodically through the process and at the end, photographs were taken for documentation purposes. Carcass degradation rates were scored based on a scoring system developed by Brown (2007). Each pile was then turned using a front-end loader while cascading the material to re-introduce oxygen into the pile. Upon turning of the compost pile, data loggers were repositioned in the core of the pile. On-going whiffle ball and composite compost samples will be collected from each pile and analyzed for SP concentrations. Composite compost samples will consist of grab samples taken from 15 collection points within each pile.

Samples were shipped to the Illinois Department of Agriculture Animal Disease Laboratory (Centralia, IL) for SP analysis using gas chromatography-mass spectrometry (GC-MS). The equipment used in the analysis were a Hewlett-Packard (HP) 6890 GC, a HP 5973 mass selective detector (MSD) and a HP 7683 autosampler (Hewlett-Packard, Andover, MA). The detection limit for compost, serum and liver samples was 5 ppb, 5 ppb and 15 ppb, respectively.

\section{Results and Discussion}

Figure 3 illustrates average daily temperature comparisons between SP treatment bins, control bins and ambient temperature. EPA regulations, under Title 40 Code of Federal Regulations Part 503, establish biosolid composting temperature standards for pathogen reduction. For class A biosolids, applied to residential areas, road banks, parks, golf courses, schools and similar areas, compost temperatures must be maintained above $55^{\circ} \mathrm{C}$ for 15 days. Class $\mathrm{B}$ biosolids, applied to grain and forage crops, pastures, grassland, fallowland and timberland, must be maintained above $40^{\circ} \mathrm{C}$ for 5 days and above $55^{\circ} \mathrm{C}$ for 4 hours during the 5 days when composting. The treatment group maintained an average daily temperature above $55^{\circ} \mathrm{C}$ for 9 days while the control group maintained an average daily temperature above $55^{\circ} \mathrm{C}$ for 12 days. Two hundred nine day temperature range and mean for the treatment group, control group and ambient temperature were $\left(13.91\right.$ to $\left.62.53 ; 34.93^{\circ} \mathrm{C}\right),\left(13.84\right.$ to $\left.67.03 ; 34.98^{\circ} \mathrm{C}\right)$, and $(-4.88$ to $\left.23.47 ; 11.12^{\circ} \mathrm{C}\right)$, respectively. Temperature levels in each treatment spiked following initiation and day 129 turning events. 


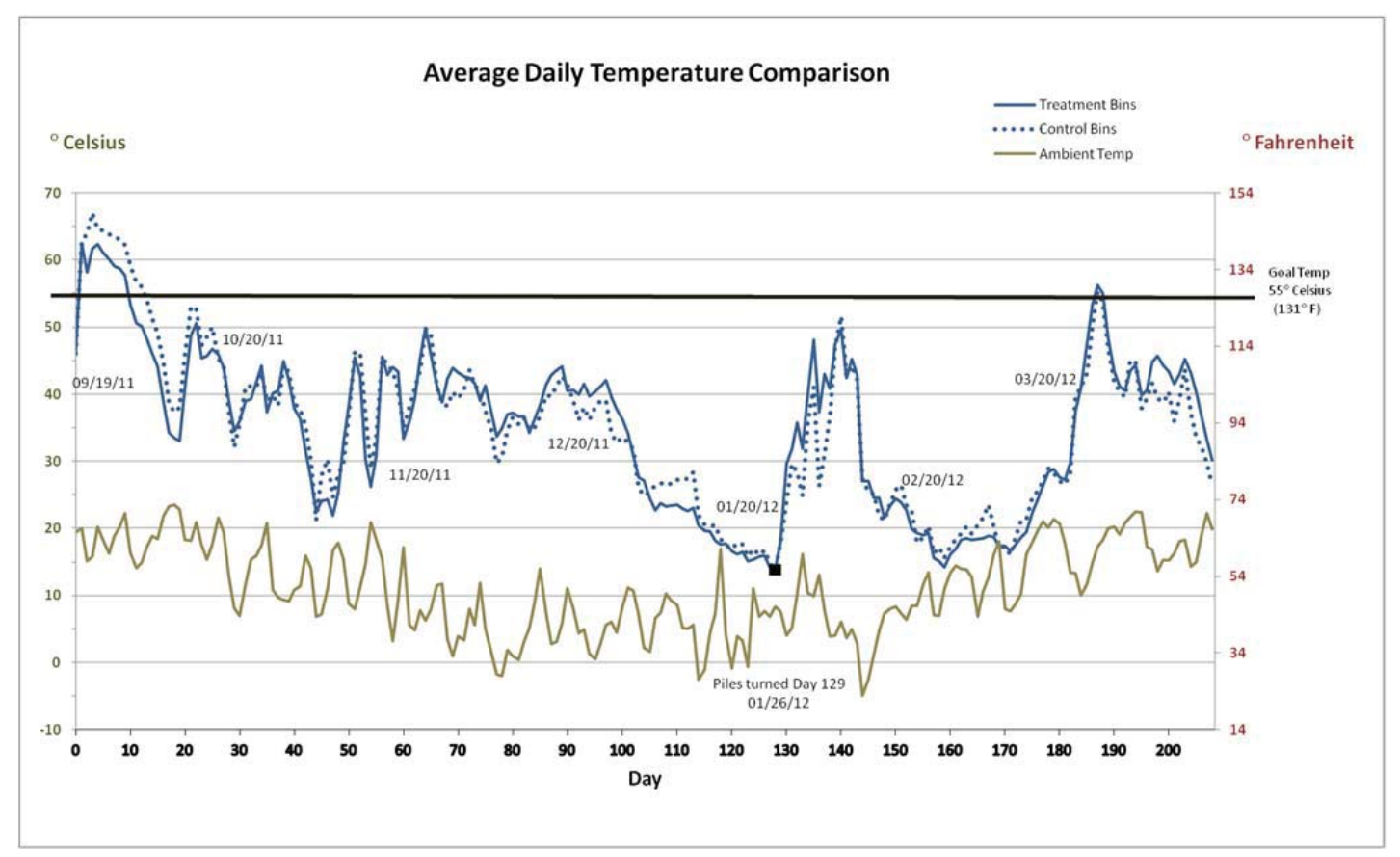

Figure 3. Average daily ambient and core compost pile temperature for sodium pentobarbital (SP) treatment and control groups.

A carcass degradation scoring system developed by Brown (2007) is listed in Table 1. Initial horse weights and carcass degradation scores following pile turning on day 129 are listed in Table 2 . The three heaviest horses $(465,558$ and $651 \mathrm{~kg})$ received a lower carcass degradation score compared to lighter weight horses $(288,400$ and $416 \mathrm{~kg})$.

Table 1. Carcass degradation scoring system.

\begin{tabular}{|c|l|}
\hline Score & Description \\
\hline 1 & $\begin{array}{l}\text { Large amounts of flesh, hide and hair present. Internal fluid still visible. Carcass still } \\
\text { discernible. }\end{array}$ \\
\hline 2 & $\begin{array}{l}\text { Flesh, hide and hair still present in smaller amounts. Carcass no longer discernible. No } \\
\text { internal fluid visible }\end{array}$ \\
\hline 3 & Slight amounts of hair and hide present. Numerous large and small bones present. \\
\hline 4 & $\begin{array}{l}\text { No hide present. Minimal hair visible. Flesh completely degraded and only large bones } \\
\text { present. }\end{array}$ \\
\hline 5 & \begin{tabular}{l} 
No flesh, hide, or hair present. Few to no large brittle bones present. \\
\hline
\end{tabular} \\
\hline
\end{tabular}


Table 2. Carcass degradation scores following pile turning on day 129.

\begin{tabular}{|c|c|c|}
\hline Bin & Horse weight $(\mathrm{kg})$ & Score \\
\hline 1 & 400 & 4 \\
\hline 2 & 558 & 3 \\
\hline 3 & 465 & 3 \\
\hline 4 & 288 & 4 \\
\hline 5 & 416 & 4 \\
\hline 6 & 651 & 3 \\
\hline
\end{tabular}

${ }^{1}$ Bins 1-3 represent sodium pentobarbital treatments. Bins 4-6 represent control treatments.

Table 3 lists horse weights and SP concentrations (dry wt.) in compost samples. Table 4 lists horse weights and SP concentrations (as-is) in liver, serum and compost samples. A complete statistical analysis will be conducted at the conclusion of the study once all soil and compost samples are collected. There does not appear to be a clear trend in SP compost concentrations from day 7 to day 129. At day 129, concentrations ranged from 13.72 to 180.73 ppm (dry wt.) and 11.15 to 108.85 ppm (as-is). Sodium pentobarbital concentrations were much higher than those reported by Cottle et al., (2010) which may be explained by the difference in sampling techniques, grab samples versus whiffle balls filled with wood chips placed underneath the carcass. Both studies administered similar sodium pentobarbital dosage levels.

Table 3. Sodium pentobarbital sample concentrations in compost samples from equine mortality static compost piles reported as dry weight.

\begin{tabular}{|c|c|c|c|c|c|c|c|}
\hline \multirow[b]{2}{*}{ Treatment $^{1}$} & \multirow[b]{2}{*}{$\begin{array}{c}\text { Horse } \\
\text { weight }(\mathrm{kg})\end{array}$} & \multicolumn{6}{|c|}{ Sodium pentobarbital concentration (dry wt. ppm) } \\
\hline & & Day 7 & Day 14 & Day 28 & Day 56 & Day 84 & Day 129 \\
\hline Bin 1 & 400 & 54.97 & 39.91 & 33.53 & 36.93 & 29.75 & 13.72 \\
\hline Bin 2 & 558 & 35.52 & 67.93 & 20.3 & 25.29 & 12.97 & 28.84 \\
\hline Bin 3 & 465 & 106.58 & 88.19 & 52.15 & 117.28 & 98.49 & 180.73 \\
\hline Bin 4 & 288 & 0 & 0 & 0 & 0 & 0 & 0 \\
\hline Bin 5 & 416 & 0 & 0 & 0 & 0 & 0 & 0 \\
\hline $\operatorname{Bin} 6$ & 651 & 0 & 0 & 0 & 0 & 0 & 0 \\
\hline
\end{tabular}

${ }^{1}$ Bins 1-3 represent sodium pentobarbital treatments. Bins 4-6 represent control treatments. 
Table 4. Sodium pentobarbital sample concentration in liver, serum and compost samples from equine mortality static compost piles reported "as-is".

\begin{tabular}{|c|c|c|c|c|c|c|c|c|c|}
\hline \multirow[b]{2}{*}{ Treatment $^{1}$} & \multirow[b]{2}{*}{$\begin{array}{c}\text { Horse } \\
\text { weight } \\
(\mathrm{kg})\end{array}$} & \multicolumn{8}{|c|}{ Sodium pentobarbital concentration (“as-is" ppm) } \\
\hline & & Liver & Serum & $\begin{array}{c}\text { Day } \\
7\end{array}$ & $\begin{array}{c}\text { Day } \\
14\end{array}$ & $\begin{array}{c}\text { Day } \\
28\end{array}$ & $\begin{array}{c}\text { Day } \\
56\end{array}$ & $\begin{array}{l}\text { Day } \\
84\end{array}$ & $\begin{array}{l}\text { Day } \\
129\end{array}$ \\
\hline Bin 1 & 400 & 91.49 & 178.25 & 30.91 & 20.78 & 18.22 & 29.40 & 24.75 & 11.15 \\
\hline Bin 2 & 558 & 14.49 & 131.4 & 18.21 & 40.43 & 14.88 & 19.47 & 8.54 & 19.45 \\
\hline Bin 3 & 465 & 56.14 & 110.63 & 51.10 & 46.13 & 34.37 & 97.08 & 74.25 & 108.85 \\
\hline Bin 4 & 288 & 0 & 0 & 0 & 0 & 0 & 0 & 0 & 0 \\
\hline Bin 5 & 416 & 0 & 0 & 0 & 0 & 0 & 0 & 0 & 0 \\
\hline $\operatorname{Bin} 6$ & 651 & 0 & 0 & 0 & 0 & 0 & 0 & 0 & 0 \\
\hline
\end{tabular}

${ }^{1}$ Bins 1-3 represent sodium pentobarbital treatments. Bins 4-6 represent control treatments

\section{Conclusions}

The preliminary findings from this study indicate that wood chips were effective at decomposing equine mortalities at 129 days of composting. Nearly all of the soft tissue was completely degraded with only large bones present. Compost temperatures met EPA class B biosolid standards for pathogen reduction. At day 129, SP still persisted in the treatment group with no clear trend of concentration reduction from day 7 to day 129. Further sampling of soil and compost piles followed by a complete statistical analysis is warranted before final conclusions related to the efficacy of composting on reducing SP concentrations in equine carcasses can be made.

\section{Acknowledgements}

Appreciation is extended to Ted Newell, Tommy Tucker, Robert Havener and Bobby Adams for their assistance with field work as well as Cheryl Ford for her assistance with data entry.

\section{References}

Brown, L.C., 2007. The effections of various co-composting materials on the decomposition of equine carcasses. Master Thesis. West Texas A\&M University, Canyon, TX.

Cottle, L.M., L.A. Baker, J.L. Pipkin, D.B. Parker, R.E. DeOtte Jr., and B.W. Auvermann, 2010. Sodium pentobarbital residues in compost piles containing carcasses of euthanized equines. International Symposium on Air Quality and Manure Management for Agriculture (cd).

Food and Drug Administration (FDA), 2003. Environmental warning added to animal euthanasia products. Available at: http://www.fda.gov/AnimalVeterinary/NewsEvents/CVMUpdates/ucm119205.htm 
Accessed April 16, 2012.

Kalbasi, A., S. Mukhtar, S.E. Hawkins and B.W. Auvermann. 2005. Carcass composting for management of farm mortalities: A review. Compost Science \& Utilization. 13(3):180193.

Payne, J. and B. Pugh, 2010. On-farm mortality composting of livestock carcasses. Oklahoma Cooperative Extension Fact Sheet. BAE-1749. Stillwater, OK. Available at: http://www.poultrywaste.okstate.edu/files/BAE1749\%200n-Farm\%20Mortality.pdf Accessed April 16, 2012. 